\title{
Theoretical Study of the Interaction between Chitosan Constituents (Glucosamine and Acetylglucosamine Dimers) and $\mathrm{Na}^{+}$Ions
}

\author{
Marwa Emmanuel*, Alexander Pogrebnoi, Tatiana Pogrebnaya \\ Department of Materials, Energy Science and Engineering, The Nelson Mandela African Institution of Science \\ and Technology, Arusha, Tanzania \\ Email: ${ }^{*}$ marwaking39eti@gmail.com, ${ }^{*}$ marwae@nm-aist.ac.tz
}

Received 10 October 2015; accepted 25 October 2015; published 30 October 2015

Copyright (C) 2015 by authors and OALib.

This work is licensed under the Creative Commons Attribution International License (CC BY).

http://creativecommons.org/licenses/by/4.0/

(c) (i) Open Access

\begin{abstract}
The interaction of dimers of glucosamine and acetylglucosamine molecules with sodium ion has been studied using the DFT/B3LYP approach. The optimization of geometrical parameters and vibrational spectra calculations were done under 6-31G(d) basis set, and energies of the reactions were obtained using 6-311++G(d, p) basis set. The enthalpies of the association reactions of the dimers of glucosamine and acetylglucosamine with $\mathrm{Na}^{+}$have been determined. The internal hydrogen bonds $\mathrm{OH} . . . \mathrm{O}$ and $\mathrm{NH}$...O have been shown to play an important role in conformational behavior of a particular molecule.
\end{abstract}

\section{Keywords}

Chitosan, Glucosamine, Acetylglucosamine, Adduct, Geometrical Parameter, Vibrational Spectra, Enthalpies of Reactions, Thermodynamic Functions

Subject Areas: Chemical Engineering \& Technology

\section{Introduction}

The functioning of any biological molecule depends fundamentally on the shape and flexibility, and further on interactions with neighboring environment, interactions provide feedback on their preferred structures and preferred bio-active conformer as well [1] [2]. For that reason several experimental and theoretical studies about interactions of different molecules have been done where different methods have been employed like nucleation, growth in liquid or gas phase to mention but a few [1]. Molecular structure and interactions lie in the area of molecular physics; it generally involves experimental methods like electronic and vibrational spectroscopy,

\footnotetext{
"Corresponding author.
}

How to cite this paper: Emmanuel, M., Pogrebnoi, A. and Pogrebnaya, T. (2015) Theoretical Study of the Interaction between Chitosan Constituents (Glucosamine and Acetylglucosamine Dimers) and $\mathrm{Na}^{+}$Ions. Open Access Library Journal, 2: e1978. http://dx.doi.org/10.4236/oalib.1101978 
mass spectrometry, and other techniques. The theoretical DFT calculations of electronic structure and force field can lead to structural assignment and more importantly, identify the interactions within the isolated molecules and between molecules and environment [3] [4]. An interesting feature and advantage of the DFT method is that it specifies the simplest structure which can demonstrate intricacies and challenges of larger and complex systems [5]. DFT provides theoretical scrutiny of the spectra to weigh against experiment, the structural view which they reflect, and the non-covalent interactions that control them [3] [6] [7].

Chitosan is a harmless and eco-friendly polysaccharide that has in recent times emerged as a promising contender for diverse applications [8] [9]. Different chitosan constituents conformers exist and they differ in the fractional content of acetylated units and the degree of polymerization [8] [10] [11]. Chitosan, a linear co-polymer of glucosamine and N-acetylglucosamine in a $\beta 1-4$ linkage obtained by N-acetylation of chitin [11] [12], is a biodegradable polysaccharide with a wide range of biomedical applications such as sutures, wound dressing, bone substitutes, tissue engineering, and gene and drug delivery systems [3] [6] [10] [13]. It is a structural material that is nowadays commonly used in chemistry, medicine, and in various technologies [2] [6]. It is biocompatible, biodegradable, nontoxic, nonflammable, nonallergenic, antimicrobial, and inexpensive [2] [13]-[18]. The chitosan constituents, glucosamine and acetylglucosamine, play an important role in multifarious applications in different fields like pharmaceutics, cosmetics, biomedicine and agriculture to mention but a few.

Previous computation exertions had been done about interaction of chitosan constituents with heavy metals, alkali and halide ions [3] [19]. The present study is the continuation of our previous work [20] where two different conformers of glucosamine monomer named $A_{X}$ and $A_{Y}$ and acetylglucosamine $B$ as well as their interraction with sodium ion were considered. Here we attempt to move a little further and investigate the interaction between dimers of glucosamine and acetylglucosamine $\left(A_{X} A_{X}, A_{Y} A_{Y}\right.$, and $\left.A_{Y} B\right)$ with sodium ion. The aim of the this work is to determine the geometrical structure, vibrational spectra, and thermodynamic properties of the dimer molecules, $A_{X} A_{X}, A_{Y} A_{Y}$, and $A_{Y} B$, as well as their adducts with sodium ion, $\mathrm{A}_{X} \mathrm{~A}_{X} \mathrm{Na}^{+}, \mathrm{A}_{Y} \mathrm{~A}_{Y} \mathrm{Na}^{+}$, and $\mathrm{A}_{Y} \mathrm{BNa}^{+}$, and the enthalpies of the association reactions between $\mathrm{Na}^{+}$and the dimers.

\section{Computational Details}

The DFT/B3LYP method under the 6-31G(d) basis set was applied for the calculations of the equilibrium geometrical parameters and vibrational spectra of dimers $A_{X} A_{X}, A_{Y} A_{Y}, A_{Y} B$ and their complexes with $\mathrm{Na}^{+}$. Embarking on this work an ensemble of low energy conformers of interest were generated using HyperChem program package [21]. Then the designed configurations were used in the optimization procedure with the Firefly software [22] partially based on the GAMESS (US) source code [23]. Vibrational spectra calculated proved the structures to be at equilibrium by the absence of imaginary frequencies. The energies of the reactions were computed with several basis sets from 6-31G(d) up to 6-311++G(d, p). For the visualization of the optimized structures, and specification of geometrical parameters and vibrational modes, the wxMacMolplot [24] and Chemcraft [25] softwares have been applied.

\section{Results and Discussion}

\subsection{Geometrical Structure of Dimers and Adducts}

The equilibrium structures of the $A_{X} A_{X}, A_{Y} A_{Y}, A_{Y} B$ and adducts $A_{X} A_{X} N^{+}, A_{Y} A_{Y} N^{+}$, and $A_{Y} B N a{ }^{+}$are shown in Figure 1, Figure 2. The selected geometrical parameters and atomic charges are given in Table 1, Table 2. The dimers and adducts comprise two rings, each of the ring made up of five carbon and one oxygen atom inserted between. These rings are fixed jointly by the glycosidic bond, the bond which ensures the stability and stiffness of this molecule [7] [10]. The glycosidic bond bends the rings in opposite direction extricating rings from each other and thus reduces repulsive forces flanked by the two.

$\mathbf{A}_{X} \mathbf{A}_{\mathbf{X}}$ and $\mathbf{A}_{\mathbf{X}} \mathbf{A}_{\mathbf{X}} \mathbf{N a}^{+}$. In the $\mathrm{A}_{X} \mathrm{~A}_{X}$ dimer, glycosidic bond forms an angle C2-O12-C15 = 119 in Figure 1(a), and Table 1, whose respective length C2-O12 and C15-O12 are $1.438 \AA$ and $1.400 \AA$ correspondingly. In the $\mathrm{A}_{X} \mathrm{~A}_{X} \mathrm{Na}^{+}$complex the geometrical parameters are not changed drastically, the angle C2-O12-C15 is $118^{\circ}$ the bond length C2-O12 is $1.426 \AA$ and C15-O12 is $1.412 \AA$. That is the attachment of $\mathrm{Na}^{+}$to the dimer does not alter significantly the shape of the glycosidic bond and this is because $\mathrm{Na}^{+}$attaches at the distance far away from the bond. In the $A_{X} A_{X}$ molecule hydroxyl group and amine group are in opposite sides to each other to reduce mutual repulsion of like charges. Amine groups are located in rather big distance between, $7.175 \AA$, thus the stable conformer of $A_{X} A_{X}$ is formed. In the rings of $A_{X} A_{X}$ the internal C-O-C groups exist, in the first ring 


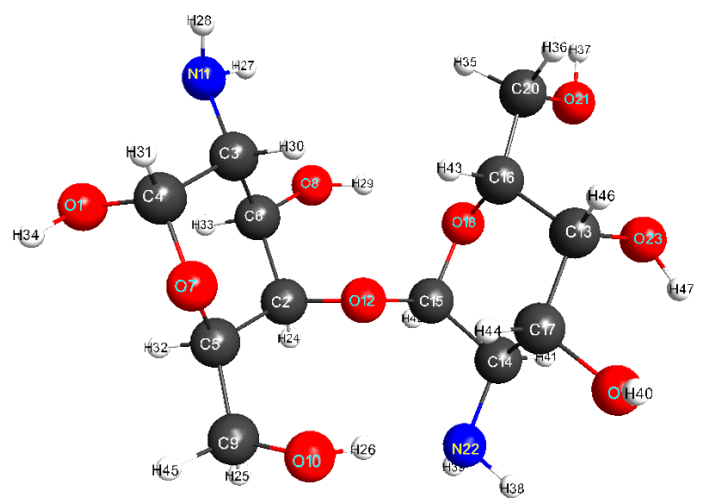

(a)

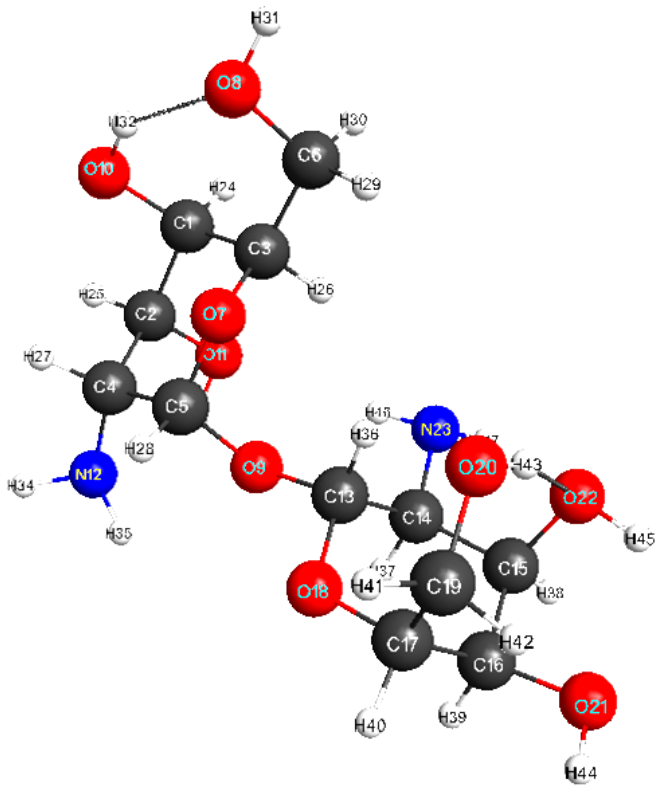

(c)

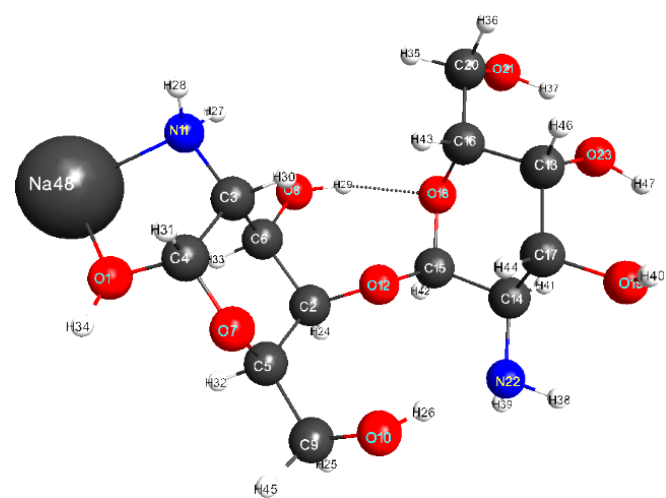

(b)

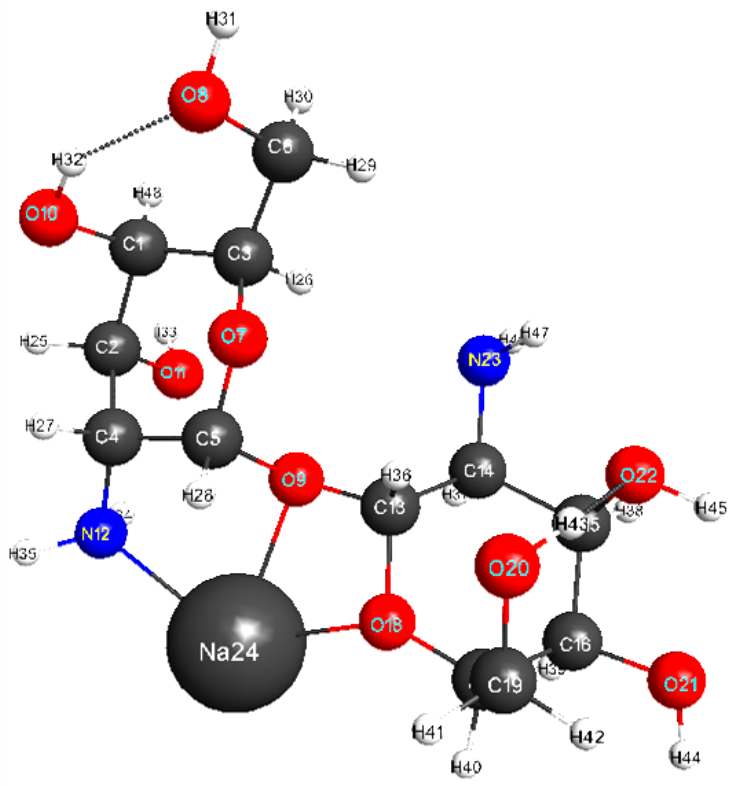

(d)

Figure 1. Equilibrium geometrical structure of the species: $A_{X} A_{X}(a) ; A_{X} A_{X} N^{+}$(b); $A_{Y} A_{Y}(c) ; A_{Y} A_{Y} N^{+}$(d).

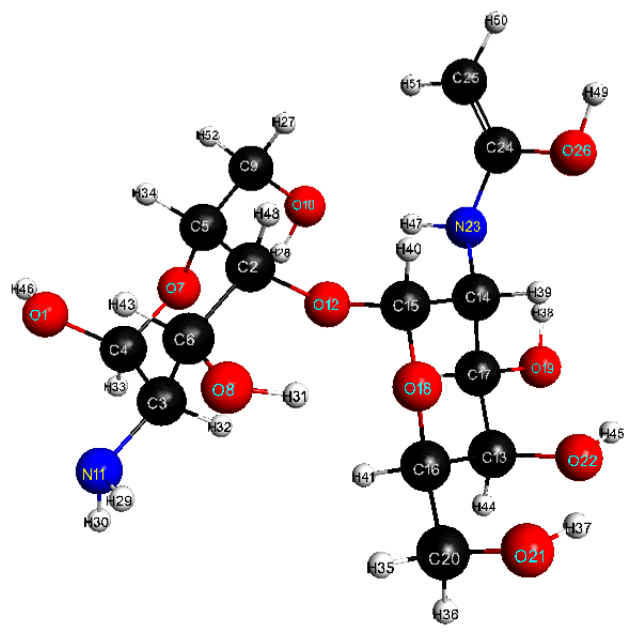

(a)

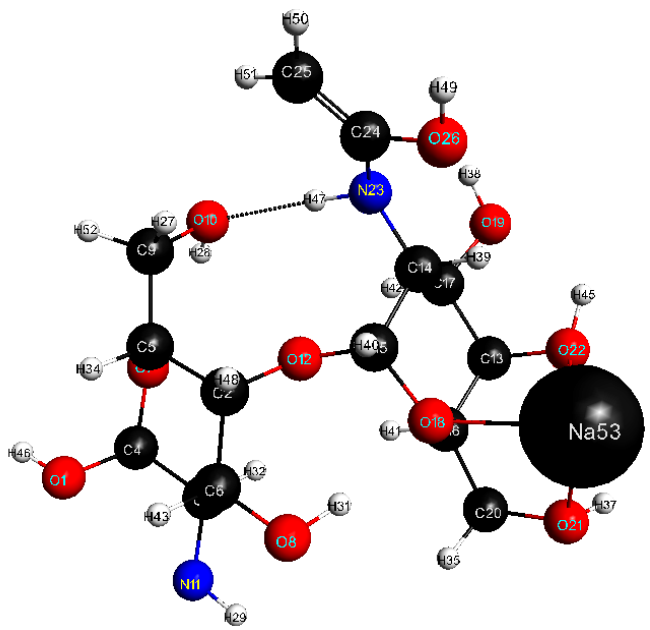

(b)

Figure 2. Equilibrium geometrical structure of the species: $\mathrm{A}_{Y} \mathrm{~B}$ (a) and $\mathrm{A}_{Y} \mathrm{BNa}^{+}$(b). 
Table 1. Selected geometrical parameters and atomic charges of $A_{X} A_{X}$ and $A_{X} A_{X} N^{+}$.

\begin{tabular}{|c|c|c|c|c|c|c|c|c|}
\hline \multirow{2}{*}{$\begin{array}{c}\text { Species } \\
\mathbf{A}_{\mathbf{X}} \mathbf{A}_{\mathbf{X}}\end{array}$} & \multicolumn{2}{|c|}{ Internuclear distance $R_{\mathrm{e}}, \AA$} & \multicolumn{2}{|c|}{ Valence angle, Deg } & \multicolumn{2}{|c|}{ Torsion angle, Deg } & \multirow{2}{*}{$\begin{array}{c}\text { Atom } \\
01\end{array}$} & \multirow{2}{*}{$\begin{array}{c}\text { Charge, a.u } \\
-0.15\end{array}$} \\
\hline & O7-C5 & 1.433 & O1-C4-O7 & 112.0 & O1-C4-O7-C5 & 61.5 & & \\
\hline & C4-O7 & 1.419 & C4-O7-C5 & 113.8 & C4-O7-C5-C2 & 60.3 & N11 & -0.19 \\
\hline & O10-C9 & 1.403 & O10-C9-C5 & 117.3 & O10-C9-C5-C2 & 64.5 & N22 & -0.33 \\
\hline & O12-C2 & 1.438 & O12-C2-C6 & 111.8 & O12-C2-C6-O8 & 59.5 & $\mathrm{O} 10$ & -0.28 \\
\hline & O8-C6 & 1.421 & O8-C6-C3 & 112.2 & O8-C6-C3-N11 & 56.6 & $\mathrm{O} 7$ & -0.02 \\
\hline & O1-C4 & 1.408 & O1-C4-C3 & 109.2 & O1-C4-C3-N11 & 53.8 & O8 & -0.17 \\
\hline & C15-O12 & 1.400 & C2-012-C15 & 119.2 & C2-O12-C15-O18 & 100.2 & $\mathrm{O} 12$ & 0.31 \\
\hline & C15-O18 & 1.423 & C15-O18-C16 & 114.3 & C15-O18-C16-C20 & -174.1 & $\mathrm{O} 23$ & -0.10 \\
\hline & C16-O18 & 1.439 & & & & & $\mathrm{C} 4$ & -0.64 \\
\hline & O21-C20 & 1.412 & O21-C20-C16 & 111.3 & O21-C20-C16-C13 & 68.2 & $\mathrm{O} 19$ & -0.24 \\
\hline & O23-C13 & 1.411 & O23-C13-C17 & 109.6 & O23-C13-C17-O19 & 48.0 & & \\
\hline & O19-C17 & 1.439 & O19-C17-C4 & 150.5 & O19-C17-C4-N22 & -75.4 & & \\
\hline \multirow[t]{14}{*}{$\mathbf{A}_{X} \mathbf{A}_{X} \mathrm{Na}^{+}$} & O7-C5 & 1.448 & O1-C4-O7 & 111.3 & O1-C4-O7-C5 & 69.2 & 01 & -0.41 \\
\hline & C4-O7 & 1.382 & C4-O7-C5 & 117.2 & C4-O7-C5-C2 & 53.8 & N11 & -0.46 \\
\hline & O10-C9 & 1.395 & O10-C9-C5 & 115.8 & O10-C9-C5-C2 & 67.0 & $\mathrm{Na}^{+}$ & 0.83 \\
\hline & O12-C2 & 1.426 & O12-C2-C6 & 111.3 & O12-C2-C6-O8 & 60.0 & N22 & -0.34 \\
\hline & O8-C6 & 1.412 & O8-C6-C3 & 110.9 & O8-C6-C3-N11 & 52.8 & $\mathrm{O} 10$ & -0.26 \\
\hline & O1-C4 & 1.460 & O1-C4-C3 & 108.2 & O1-C4-C3-N11 & 50.9 & O7 & 0.03 \\
\hline & C15-O12 & 1.412 & C2-012-C15 & 117.9 & C2-O12-C16-O18 & 125.1 & O8 & -0.15 \\
\hline & O18-C15 & 1.417 & O18-C15-C14 & 111.5 & O18-C15-C14-N22 & 178.3 & $\mathrm{O} 18$ & 0.11 \\
\hline & C16-O18 & 1.445 & C15-O18-C16 & 115.9 & C15-O18-C16-C20 & 177.3 & $\mathrm{O} 21$ & -0.13 \\
\hline & O21-C20 & 1.402 & O21-C20-C16 & 114.4 & O21-C20-C16-C13 & 70.3 & $\mathrm{O} 23$ & -0.18 \\
\hline & O23-C13 & 1.421 & O23-C13-C17 & 109.7 & O23-C13-C17-O19 & 48.0 & $\mathrm{O} 19$ & -0.24 \\
\hline & $\mathrm{Na}^{+}-\mathrm{O} 1$ & 2.227 & O1-Na ${ }^{+}-\mathrm{N} 11$ & 76.7 & O1-Na ${ }^{+}-\mathrm{N} 11-\mathrm{C} 3$ & 22.4 & $\mathrm{C} 4$ & -0.58 \\
\hline & $\mathrm{Na}^{+}-\mathrm{N} 11$ & 2.335 & & & $\mathrm{C} 4-\mathrm{O} 1-\mathrm{Na}^{+}-\mathrm{N} 11$ & 3.5 & & \\
\hline & O8-H29...018 & 1.853 & & & & & & \\
\hline \multirow[t]{8}{*}{$\mathbf{A}_{\mathbf{Y}} \mathbf{A}_{\mathbf{Y}}$} & C5-O9 & 1.429 & C5-O9-C13 & 117.4 & C5-O9-C13-O18 & 84.0 & $\mathrm{O} 7$ & 0.13 \\
\hline & C13-O7 & 1.398 & & & & & O9 & 0.09 \\
\hline & C3-O7 & 1.439 & C3-O7-C5 & 115.2 & C3-O7-C5-C4 & -54.8 & $\mathrm{O} 10$ & -0.16 \\
\hline & C5-O7 & 1.400 & & & & & $\mathrm{O} 18$ & -0.01 \\
\hline & C13-O18 & 1.434 & C13-O18-C17 & 114.8 & C13-O18-C17-C16 & -59.1 & $\mathrm{~N} 12$ & -0.39 \\
\hline & C17-O18 & 1.428 & & & & & N23 & -0.30 \\
\hline & O10-H32...O8 & 1.865 & & & & & & \\
\hline & O20-H43...O22 & 1.820 & & & & & & \\
\hline \multirow[t]{11}{*}{$\mathrm{A}_{Y} \mathrm{~A}_{Y} \mathrm{Na}^{+}$} & C5-O9 & 1.453 & C5-O9-C13 & 114.6 & C5-O9-C13-O18 & 103.3 & O7 & 0.19 \\
\hline & C13-O7 & 1.406 & & & & & O9 & 0.06 \\
\hline & C3-O7 & 1.446 & C3-O7-C5 & 115.4 & C3-O7-C5-C4 & -53.2 & $\mathrm{O} 10$ & -0.12 \\
\hline & C5-O7 & 1.382 & & & & & $\mathrm{O} 18$ & -0.18 \\
\hline & C13-018 & 1.462 & C13-O18-C17 & 116.7 & C13-O18-C17-C16 & -59.7 & N12 & -0.49 \\
\hline & C17-O18 & 1.450 & $\mathrm{~N} 12-\mathrm{Na}^{+}-\mathrm{O} 18$ & 129.2 & N12-Na+-O9-O18 & 162.3 & N23 & -0.19 \\
\hline & O10-H32...O8 & 1.853 & N12-Na $-\mathrm{O} 9$ & 73.1 & & & $\mathrm{Na}^{+}$ & 0.83 \\
\hline & O20-H43...O22 & 1.864 & $\mathrm{O} 9-\mathrm{Na}^{+}-\mathrm{O} 18$ & 58.9 & & & & \\
\hline & $\mathrm{Na}^{+}-\mathrm{O} 9$ & 2.335 & & & & & & \\
\hline & $\mathrm{Na}^{+}-\mathrm{O} 18$ & 2.253 & & & & & & \\
\hline & $\mathrm{Na}^{+}-\mathrm{N}$ & 2.347 & & & & & & \\
\hline
\end{tabular}


Table 2. Selected geometrical parameters and atomic charges of $\mathrm{A}_{Y} \mathrm{~B}$ and $\mathrm{A}_{\mathrm{Y}} \mathrm{BNa}^{+}$.

\begin{tabular}{|c|c|c|c|c|c|c|c|c|}
\hline $\begin{array}{c}\text { Species } \\
\mathbf{A}_{\mathbf{Y}} \mathbf{B} \\
\end{array}$ & \multicolumn{2}{|c|}{ Internuclear distance, $R_{\mathrm{e}}, \AA$} & \multicolumn{2}{|c|}{ Valence angle, Deg } & \multicolumn{2}{|c|}{ Torsion angle, Deg } & $\begin{array}{c}\text { Atom } \\
\mathrm{O} 1\end{array}$ & $\begin{array}{c}\text { Charge, a.u } \\
-0.37\end{array}$ \\
\hline & O1-C4 & 1.401 & O1-C4-C3 & 109.7 & O1-C4-C3-N11 & 55.0 & $\mathrm{O} 7$ & -0.42 \\
\hline & $\mathrm{C} 4-\mathrm{O} 7$ & 1.401 & $\mathrm{C} 4-\mathrm{O} 7-\mathrm{C} 5$ & 109.7 & C4-O7-C5-C9 & 55.0 & $\mathrm{O} 10$ & -0.42 \\
\hline & O10-С9 & 1.423 & O10-C9-C5 & 113.2 & O10-C9-C5-C2 & 75.2 & N11 & -0.44 \\
\hline & N11-C3 & 1.457 & N11-C3-C6 & 109.2 & N11-C3-C6-08 & 54.0 & $\mathrm{O} 12$ & -0.42 \\
\hline & C2-O12 & 1.438 & C2-O12-C15 & 118.3 & C2-O12-C15-O18 & 89.0 & 018 & -0.42 \\
\hline & C15-O18 & 1.423 & C15-O18-C16 & 116.6 & C15-O18-C16-C20 & 177.6 & O19 & -0.43 \\
\hline & C15-012 & 1.408 & & & & & & \\
\hline & O21-C20 & 1.406 & O21-C20-C16 & 114.6 & O21-C20-C16-C13 & 67.6 & $\mathbf{0 2 1}$ & -0.40 \\
\hline & $\mathrm{O} 22-\mathrm{C} 13$ & 1.425 & O22-C13-C17 & 109.4 & O22-C13-C17-O19 & 50.9 & $\mathbf{O 2 2}$ & -0.45 \\
\hline & O19-C17 & 1.421 & O19-C17-C14 & 110.2 & O19-C17-C14-N23 & 59.5 & N23 & -0.44 \\
\hline & O26-C24 & 1.369 & O26-C24-N23 & 111.1 & O26-C24-N23-C14 & 34.9 & O26 & -0.38 \\
\hline \multirow[t]{17}{*}{$\mathrm{A}_{\mathrm{Y}} \mathrm{BNa}^{+}$} & & & & & & & $\mathrm{Na}^{+}$ & 0.74 \\
\hline & O1-C4 & 1.394 & O1-C4-C3 & 109.3 & O1-C4-C3-N11 & 54.6 & $\mathrm{O} 1$ & -0.44 \\
\hline & $\mathrm{O} 1-\mathrm{C} 4$ & 1,394 & O1-C4-O7 & 111.6 & O1-C4-O7-C5 & 59.4 & $\mathrm{O} 7$ & -0.36 \\
\hline & $\mathrm{C} 4-\mathrm{O} 7$ & 1.435 & $\mathrm{C} 4-\mathrm{O} 7-\mathrm{C} 5$ & 113.6 & C4-O7-C5-C9 & -171.2 & $\mathrm{O} 8$ & -0.43 \\
\hline & O10-C9 & 1.425 & O10-C9-C5 & 113.3 & O10-C9-C5-C2 & 74.4 & $\mathrm{O} 10$ & -0.47 \\
\hline & N11-C3 & 1.451 & N11-C3-C6 & 109.0 & N11-C3-C6-08 & 57.2 & N11 & -0.38 \\
\hline & C2-O12 & 1.457 & C2-O12-C15 & 119.2 & C2-O12-C15-O18 & 96.9 & $\mathrm{O} 12$ & -0.10 \\
\hline & N23-H47...O10 & 1.930 & & & & & & \\
\hline & C15-012 & 1.378 & & & & & & \\
\hline & C15-O18 & 1.475 & C15-O18-C16 & 113.1 & C15-O18-C16-C20 & -168.4 & 018 & -0.40 \\
\hline & O21-C20 & 1.440 & O21-C20-C16 & 113.9 & O21-C20-C16-C13 & 60.8 & O19 & -0.45 \\
\hline & $\mathrm{O} 22-\mathrm{C} 13$ & 1.444 & O22-C13-C17 & 108.5 & O22-C13-C17-O19 & 51.6 & 021 & -0.49 \\
\hline & O19-C17 & 1.417 & O19-C17-C14 & 109.8 & O19-C17-C14-N23 & 64.0 & $\mathbf{0 2 2}$ & -0.61 \\
\hline & O26-C24 & 1.373 & O26-C24-N23 & 111.1 & O26-C24-N23-C14 & 26.8 & N23 & -0.21 \\
\hline & $\mathrm{Na}^{+}-\mathrm{O} 18$ & 2.351 & $\mathrm{O} 22-\mathrm{Na}^{+}-\mathrm{O} 21$ & 76.4 & $\mathrm{O} 22-\mathrm{Na}^{+}-\mathrm{O} 21-\mathrm{C} 20$ & -68.1 & O26 & -0.50 \\
\hline & $\mathrm{Na}^{+}-\mathrm{O} 21$ & 2.276 & $\mathrm{O} 22-\mathrm{Na}^{+}-\mathrm{O} 18$ & 76.0 & & & & \\
\hline & $\mathrm{Na}^{+}-\mathrm{O} 22$ & 2.312 & $\mathrm{O} 21-\mathrm{Na}^{+}-\mathrm{O} 18$ & 77.9 & & & & \\
\hline
\end{tabular}

C4-O7-C5 angle is $114^{\circ}$, its respective bond lengths are C4-O7 = $1.419 \AA$ and $\mathrm{C} 5-\mathrm{O} 7=1.433 \AA$, in the other ring the $\mathrm{C} 15-\mathrm{O} 18-\mathrm{C} 16$ angle is the same and the bond lengths are $1.423 \AA$ for $\mathrm{C} 15-\mathrm{O} 18$ and $1.439 \AA$ for C16-O18. That is the internal C-O-C fragments are alike in both rings of $A_{X} A_{X}$ implying to have the same chemical environment before $\mathrm{Na}^{+}$attachment.

In $\mathrm{A}_{\mathrm{X}} \mathrm{A}_{\mathrm{X}} \mathrm{Na}^{+}$adduct, the position of the $\mathrm{Na}^{+}$connection is ascribed to the negative charges of the $\mathrm{N} 11, \mathrm{O} 1$ and C4 (Table 1) and appropriate internuclear separations. The attachment of $\mathrm{Na}^{+}$creates two new bonds $\mathrm{Na}^{+}-\mathrm{O} 1$ and $\mathrm{Na}^{+}$-N11. Compared to $\mathrm{A}_{X} \mathrm{~A}_{\mathrm{X}}$, in $\mathrm{A}_{\mathrm{X}} \mathrm{A}_{\mathrm{X}} \mathrm{Na}^{+}$adduct the attached $\mathrm{Na}^{+}$results in some modification to the original structure, the $\mathrm{C} 4-\mathrm{O} 7-\mathrm{C} 5=117^{\circ}$ in the first ring whose respective bond lengths are $\mathrm{C} 4-\mathrm{O} 7=1.382 \AA$ and $\mathrm{C} 5-\mathrm{O} 7=1.448 \AA$, and the next ring $\mathrm{C} 15-\mathrm{O} 18-\mathrm{C} 16=116^{\circ}$ whose respective bond lengths are $1.417 \AA$ for C15-O18 and $1.445 \AA$ for C16-O18. Furthermore in the adduct $\mathrm{A}_{X} \mathrm{~A}_{X} \mathrm{Na}^{+}$, the internal hydrogen bond $\mathrm{O} 8$ H29...O18 (1.853 $\AA)$ is formed which increases the adduct stability and stiffness.

$\mathbf{A}_{\mathbf{Y}} \mathbf{A}_{\mathbf{Y}}$ and $\mathbf{A}_{\mathbf{Y}} \mathbf{A}_{\mathbf{Y}} \mathbf{N a}^{+}$. In the dimer $A_{Y} A_{Y}$ the amine groups are separated by distance of $4.979 \AA$ that is significantly less as compared to $A_{X} A_{X}\left(7.175 \AA\right.$ ). This may lead to decrease in the stability of the dimer $A_{Y} A_{Y}$ because of the repulsive force experienced between amine groups. Also this dimer has two hydrogen bonds O10-H32...O8 and O20-H43...O22 whose respective lengths are 1.865 and $1.820 \AA$. The formation of these in- 
ternal hydrogen bonds favors the stability of the dimer. In the glycosidic bond of $\mathrm{A}_{Y} \mathrm{~A}_{Y}$, the angle C5-O9-C13 is equal to $117^{\circ}$ and the bond lengths C5-O9 and C13-O9 are $1.438 \AA$ and $1.398 \AA$ correspondingly (Table 1) while in the $\mathrm{A}_{Y} \mathrm{~A}_{\mathrm{Y}} \mathrm{Na}^{+}$complex, the similar angle C5-O9-C13 is $115^{\circ}$ and the bond lengths are C5-O9 $=1.453 \AA$ and C13-O9 = $1.406 \AA$. Thus akin to $\mathrm{A}_{X} \mathrm{~A}_{X} \mathrm{Na}^{+}$the attachment of $\mathrm{Na}^{+}$to $\mathrm{A}_{Y} \mathrm{~A}_{\mathrm{Y}}$ does not bring essential change in the parameters of the glycosidic bond. At the same time contrary to $\mathrm{A}_{X} \mathrm{~A}_{X} \mathrm{Na}^{+}$, the position of $\mathrm{Na}^{+}$connection to $A_{Y} A_{Y}$ is close to the glycosidic bond; it attaches to two oxygen atoms (one of the glycosidic bond and another of the ring) and to the nitrogen atom connected with the second ring.

In $\mathrm{A}_{Y} \mathrm{~A}_{Y} \mathrm{Na}^{+}$adduct, the position of the $\mathrm{Na}^{+}$attachment is credited to the negative charge -0.39 of the N12 in the dimer $A_{Y} A_{Y}$ and the appropriate internuclear separations and steric factors as well. Three new bonds are formed: $\mathrm{Na}^{+}-\mathrm{O} 9, \mathrm{Na}^{+}-\mathrm{O} 18$ and $\mathrm{Na}^{+}-\mathrm{N} 12$ with internuclear separations $2.335 \AA, 2.253 \AA$, and $2.347 \AA$, respectively. Two hydrogen bonds $\mathrm{O} 10-\mathrm{H} 32 \ldots \mathrm{O} 8$ and $\mathrm{O} 20-\mathrm{H} 43 \ldots \mathrm{O} 22$ remain in adduct $\mathrm{A}_{Y} \mathrm{~A}_{Y} \mathrm{Na}^{+}$, and their respective lengths do not change remarkably as compared to $A_{Y} A_{Y}$.

$\mathbf{A}_{\mathbf{Y}} \mathbf{B}$ and $\mathbf{A}_{\mathbf{Y}} \mathbf{B N a}^{+}$. The equilibrium structures of the $\mathrm{A}_{\mathrm{Y}} \mathrm{B}$ complex and the $\mathrm{A}_{\mathrm{Y}} \mathrm{BNa}^{+}$adduct are shown in Figure 2; and the selected geometrical parameters and atomic charges are given in Table 2. In the glycosidic bond of $\mathrm{A}_{\mathrm{Y}} \mathrm{B}$ connecting two rings the angle $\mathrm{C} 2-\mathrm{O} 12-\mathrm{C} 15$ is equal to $118^{\circ}$, and bond lengths are $\mathrm{C} 2-\mathrm{O} 12=$ $1.438 \AA$ and $\mathrm{O} 12-\mathrm{C} 15=1.408 \AA$. In the $\mathrm{A}_{\mathrm{Y}} \mathrm{BNa}^{+}$, the $\mathrm{C} 2-\mathrm{O} 12-\mathrm{C} 18$ angle is $119^{\circ}$ and the respective bond lengths C2-O12 and O12-C15 are $1.457 \AA$ and $1.378 \AA$, thus slight change in the C-O-C parameters are noticed when $\mathrm{Na}^{+}$is attached. In $\mathrm{A}_{Y} \mathrm{BNa}^{+}$, three bonds are formed between $\mathrm{Na}^{+}$and negatively charged oxygen atoms O18, O21, O22. In $\mathrm{A}_{\mathrm{Y}} \mathrm{BNa}^{+}$adduct the amino groups are located far apart at the distance of $7.244 \AA$ between two nitrogen atoms to ebb electron-electron repulsion. Whereas in $A_{Y} B$ molecule there is no internal hydrogen bond, and in its adduct the hydrogen bond $\mathrm{N} 23-\mathrm{H} 47 \ldots \mathrm{O} 10$ is formed; this connotes that attachment of $\mathrm{Na}^{+}$stabilizes the species.

\subsection{Vibration Spectra of Dimers and Adducts}

In the calculated vibrational spectra there were no imaginary frequencies revealing the equilibrium geometrical structures of the species. The theoretical spectra of the dimer molecules and adducts with $\mathrm{Na}^{+}$ion are presented in Figures 3-5. The general feature of all these spectra is an existence of three regions of vibrational modes, which are approximately (i) below $1700 \mathrm{~cm}^{-1}$, (ii) about $3000 \mathrm{~cm}^{-1}$, and (iii) above $3300 \mathrm{~cm}^{-1}$. The assignment of the most intensive peaks is considered below.

$\mathbf{A}_{X} \mathbf{A}_{X}$ and $\mathbf{A}_{X} \mathbf{A}_{X} \mathbf{N a}^{+}$. The vibrational spectra of $A_{X} A_{X}$ and $A_{X} A_{X} N a^{+}$adducts are shown in Figure 3 . As is seen, majority of bands are located at a low frequency region $100-1690 \mathrm{~cm}^{-1}$ which correspond to $\mathrm{O}-\mathrm{H}$ rocking, $\mathrm{NH}_{2}$ scissoring, and ring bending vibrations. For the dimer $\mathrm{A}_{\mathrm{X}} \mathrm{A}_{\mathrm{X}}$ the strongest peak seen at $1067 \mathrm{~cm}^{-1}$ is ascribed to bending of the first ring, and the subsequent peak at $1352 \mathrm{~cm}^{-1}$ is assigned to the bending of the second ring. An intricate vibration mode at $717 \mathrm{~cm}^{-1}$ relates to the bending of different fragments of the molecule. The middle region ranges from $2900-3100 \mathrm{~cm}^{-1}$ in both $A_{X} A_{X}$ and $A_{X} A_{X} N a^{+}$adduct; the most intensive peak relates to $\mathrm{C}-\mathrm{H}$ stretching at about $3034 \mathrm{~cm}^{-1}$. The higher frequency region ranges between $3400-3750 \mathrm{~cm}^{-1}$ for both $A_{X} A_{X}$ and the $A_{X} A_{X} N a^{+}$adduct where very intense O-H stretching modes are seen at about $3500 \mathrm{~cm}^{-1}$ and 3474 $\mathrm{cm}^{-1}$ for $A_{X} A_{X}$ and $A_{X} A_{X} N^{+}$, respectively. Also the peaks at $3581 \mathrm{~cm}^{-1}\left(A_{X} A_{X}\right)$ and $3444 \mathrm{~cm}^{-1}\left(A_{X} A_{X} N a^{+}\right)$observed are assigned to the combination of $\mathrm{O}-\mathrm{H}$ and $\mathrm{N}-\mathrm{H}$ stretching modes.

$\mathbf{A}_{\mathbf{Y}} \mathbf{A}_{\mathbf{Y}}$ and $\mathbf{A}_{\mathbf{Y}} \mathbf{A}_{\mathbf{Y}} \mathrm{Na}^{+}$. The vibrational spectra of $\mathrm{A}_{Y} \mathrm{~A}_{Y}$ and $\mathrm{A}_{Y} \mathrm{~A}_{Y} \mathrm{Na}^{+}$are shown in Figure 4. Majority of the vibrational bands manifests at the first frequency region. The most intensive vibrational peak is seen at 1089 $\mathrm{cm}^{-1}$ associated to bending of the ring, other peaks are seen also at $186 \mathrm{~cm}^{-1}$ relating to O-H rocking and ring bending, at $800 \mathrm{~cm}^{-1} \mathrm{NH}_{2}$ wagging, O-H rocking and a vibration band at $\sim 1670 \mathrm{~cm}^{-1}$ assigned to the $\mathrm{NH}_{2}$ scissoring. The similar bands are seen in $\mathrm{A}_{Y} \mathrm{~A}_{Y} \mathrm{Na}^{+}$adduct. In the middle region at about $3000 \mathrm{~cm}^{-1} \mathrm{C}-\mathrm{H}$ stretching vibrational modes are seen for both $\mathrm{A}_{Y} \mathrm{~A}_{Y}$ and $\mathrm{A}_{\mathrm{Y}} \mathrm{A}_{\mathrm{Y}} \mathrm{Na}^{+}$adduct; and in the higher frequency region $\mathrm{O}-\mathrm{H}$ and $\mathrm{NH}_{2}$ stretching vibrations may be observed between $3400-3750 \mathrm{~cm}^{-1}$ in both cases.

$\mathbf{A}_{\mathbf{Y}} \mathbf{B}$ and $\mathbf{A}_{\mathbf{Y}} \mathbf{B N a}^{+}$. In the IR spectra of $\mathrm{A}_{Y} \mathrm{~B}$ and $\mathrm{A}_{Y} \mathrm{BNa}^{+}$the most intensive bands are seen in low and high frequency regions (Figure 5). In the spectrum of $A_{Y} B$ molecule, the peak at $1741 \mathrm{~cm}^{-1}$ is assigned to a combination of $\mathrm{C}=\mathrm{C}$ bond stretching and $\mathrm{N}-\mathrm{H}$ rocking, the next band at $1035 \mathrm{~cm}^{-1}$ corresponds to the combination of $\mathrm{C}-\mathrm{O}$ stretching and ring bending. Other peaks are ascribed to $\mathrm{O}-\mathrm{H}$ rocking, $\mathrm{N}-\mathrm{H}$ scissoring, and knotty vibration mode of the ring. In the middle region the $\mathrm{C}-\mathrm{H}$ stretching vibration is observed at $3019 \mathrm{~cm}^{-1}$ for $A_{Y} B$ and at $3061 \mathrm{~cm}^{-1}$ for the adduct. Lastly in the third region, $\mathrm{N}-\mathrm{H}$, and $\mathrm{O}-\mathrm{H}$ stretching vibration modes of the $\mathrm{A}_{\mathrm{Y}} \mathrm{B}$ are 


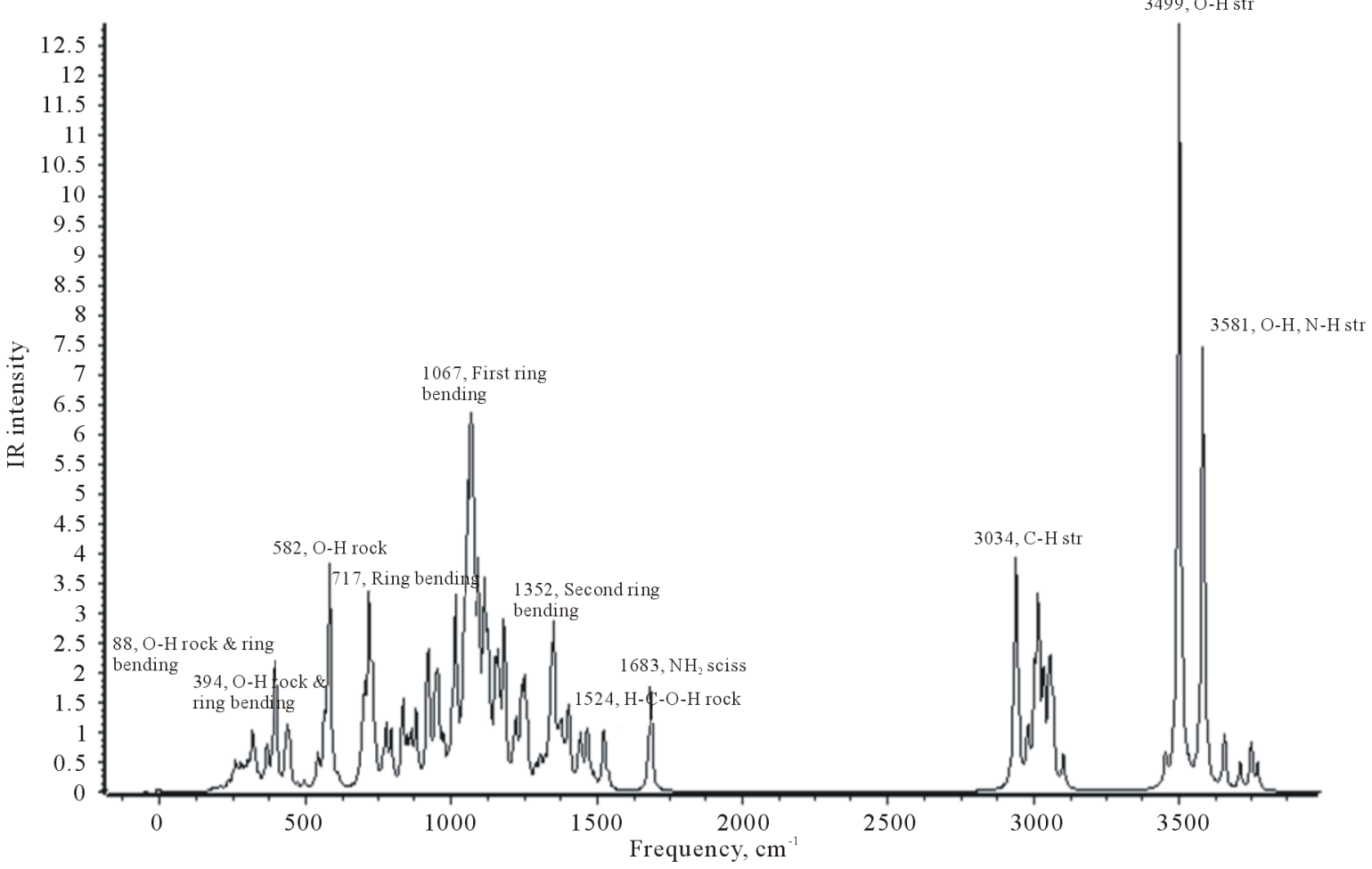

(a)

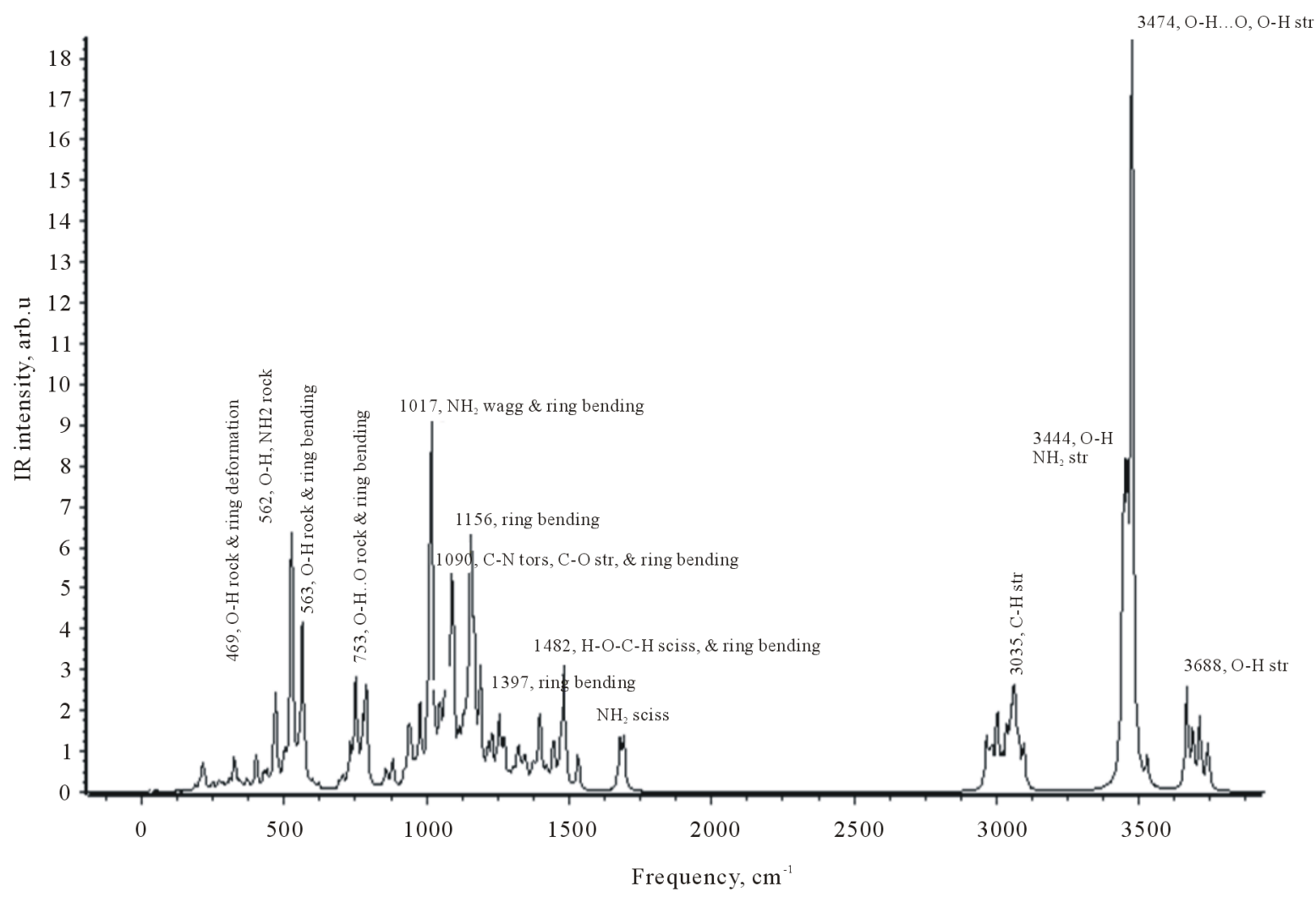

(b)

Figure 3. Theoretical IR spectra of $\mathrm{A}_{X} \mathrm{~A}_{X}$ (a) and $\mathrm{A}_{X} \mathrm{~A}_{X} \mathrm{Na}^{+}$(b). 


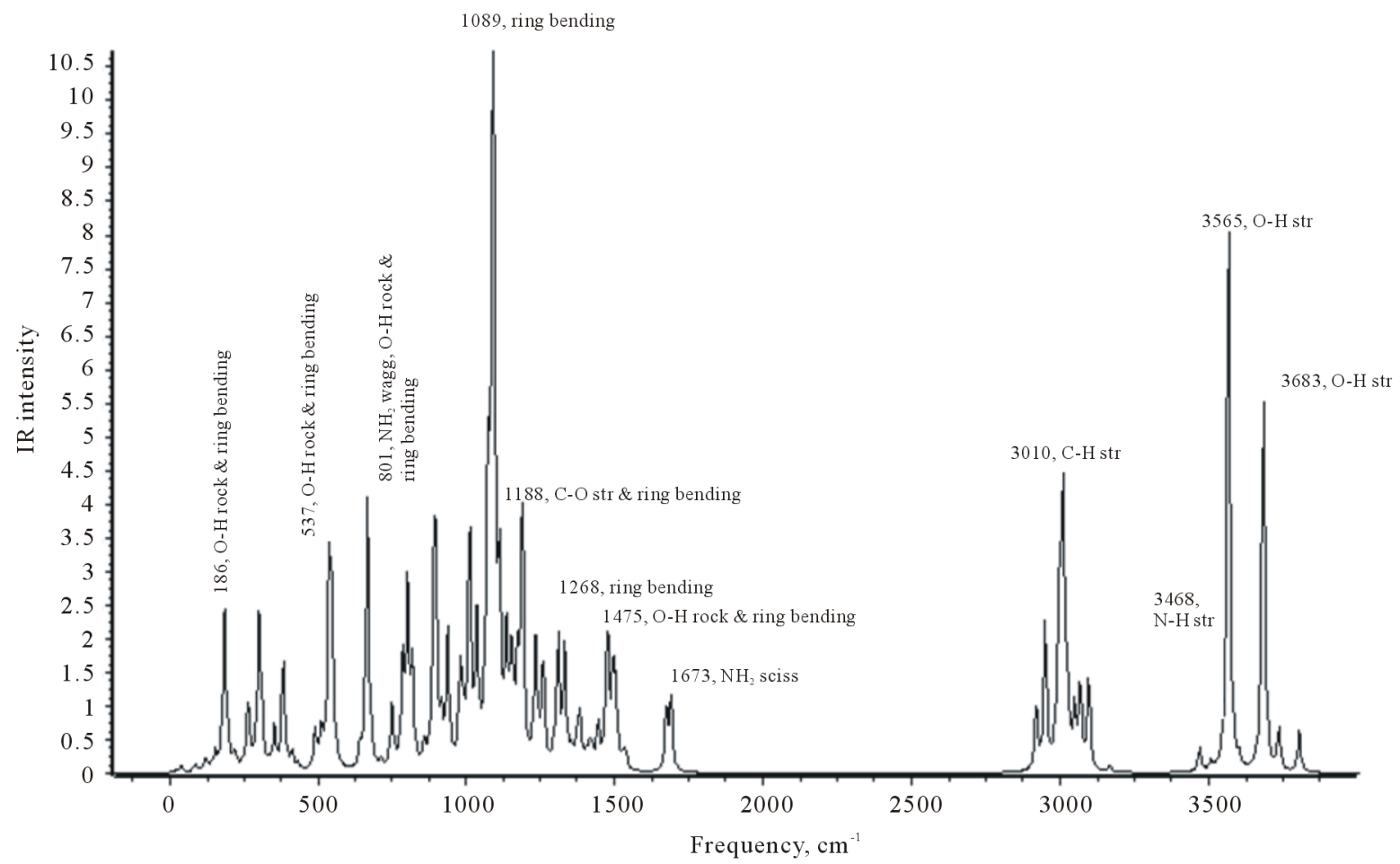

(a)

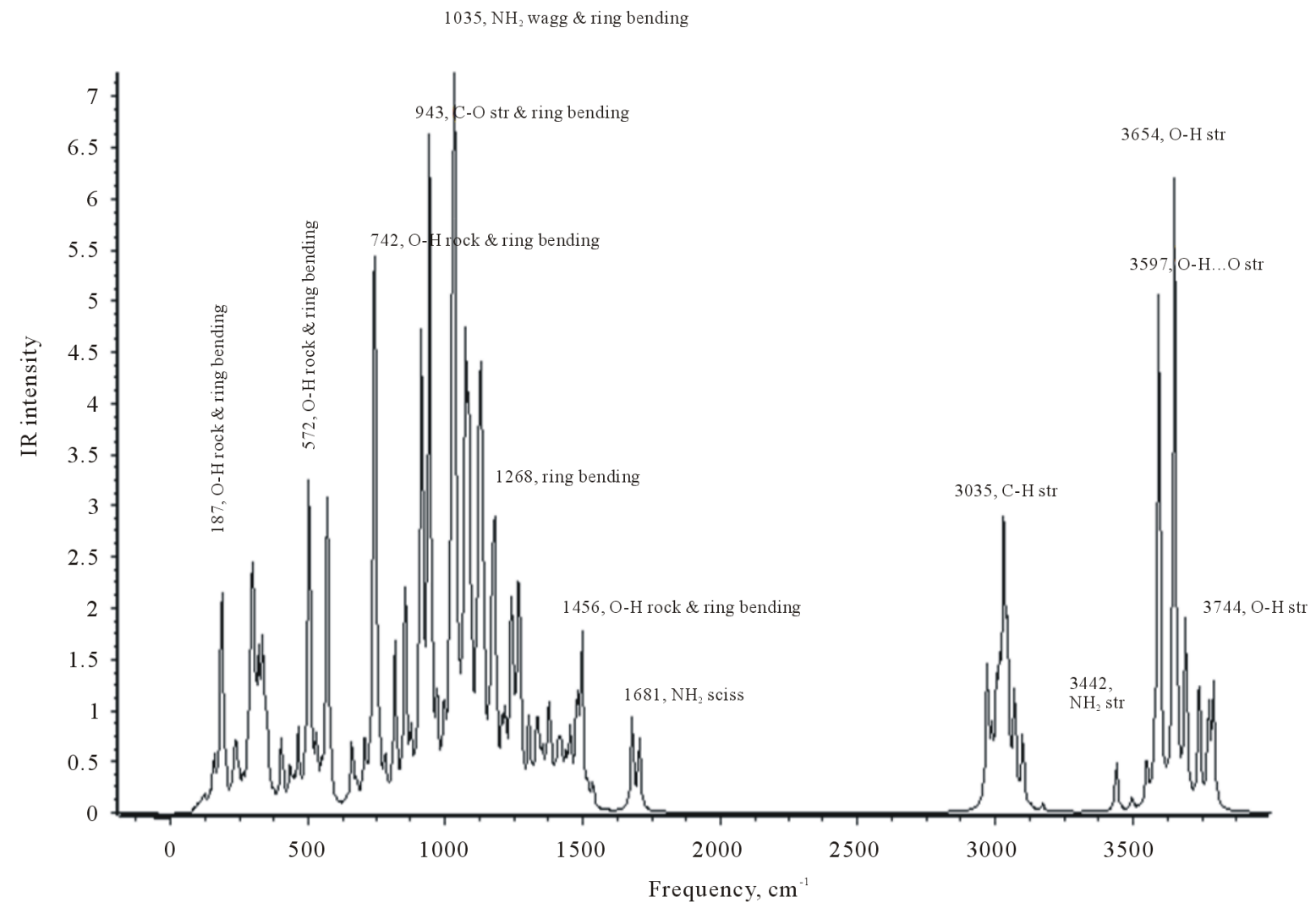

(b)

Figure 4. Theoretical IR spectra of $\mathrm{A}_{Y} \mathrm{~A}_{Y}(\mathrm{a})$ and $\mathrm{A}_{Y} \mathrm{~A}_{Y} \mathrm{Na}^{+}$(b). 


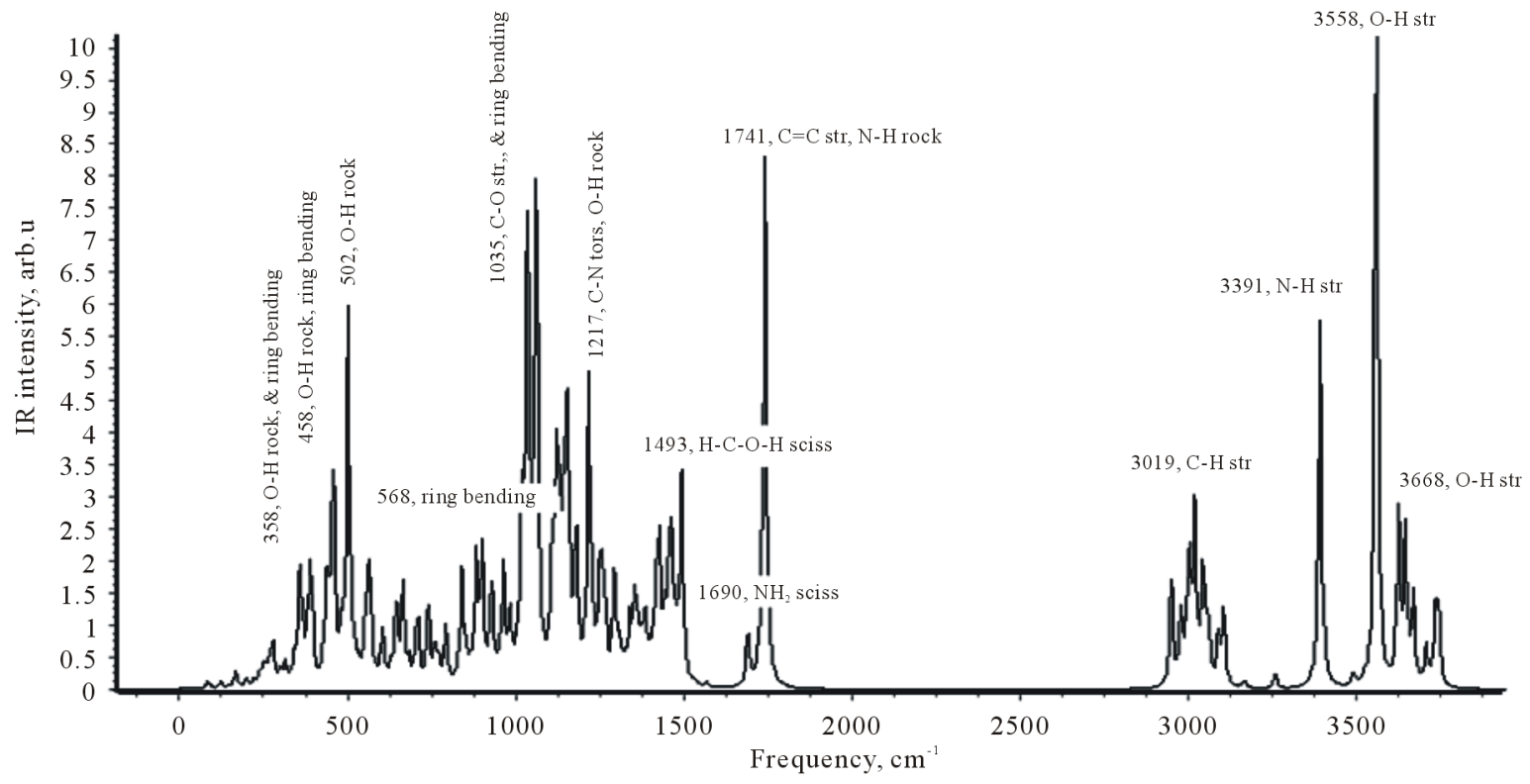

(a)

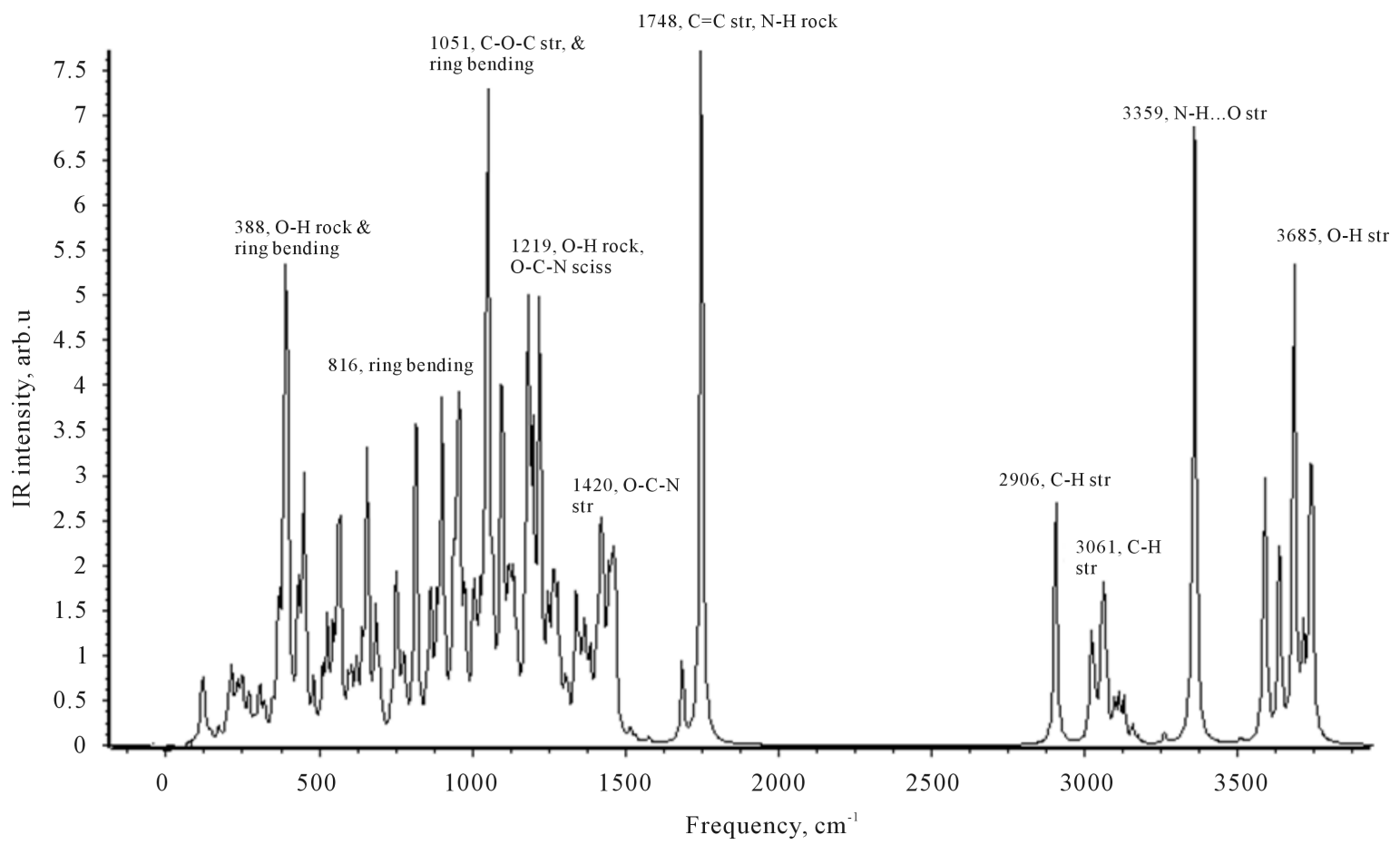

(b)

Figure 5. Theoretical IR spectra of $\mathrm{A}_{\mathrm{Y}} \mathrm{B}(\mathrm{a})$, and $\mathrm{A}_{\mathrm{Y}} \mathrm{BNa}^{+}$(b).

seen between $3391-3668 \mathrm{~cm}^{-1}$ while for $\mathrm{A}_{Y} \mathrm{BNa}^{+}$adduct the frequency $3359 \mathrm{~cm}^{-1}$ is assigned to the stretching vibration of NH...O (hydrogen bond).

Concluding this section on the spectra of the dimer molecules and the adducts with $\mathrm{Na}^{+}$ion, some similarities may be noted which are apparently due to the same functional groups of atoms, $\mathrm{NH}_{2}, \mathrm{CH}, \mathrm{OH}, \mathrm{COC}$, and other fragments, and the structural resemblance of the species as well. In the $\mathrm{AANa}^{+}$, and $\mathrm{ABNa}^{+}$adducts, the $\mathrm{Na}^{+}$ion only participates in low frequency vibrations, less than $395 \mathrm{~cm}^{-1}$ of low IR intensity. Worth to mention here that the findings of this study are in accordance with the theoretical spectra of the glucosamine molecules A, AA, 
and AAA [7], and $\mathrm{ANa}^{+}$and $\mathrm{BNa}^{+}$adducts [20] as well with the experimental IR spectra of chitosan [26] [27].

\subsection{Thermodynamics of Association Reactions}

The reactions of the sodium ion attachment to the dimer molecules were considered:

$$
\begin{aligned}
& \mathrm{A}_{\mathrm{X}} \mathrm{A}_{\mathrm{X}}+\mathrm{Na}^{+} \rightarrow \mathrm{A}_{\mathrm{X}} \mathrm{A}_{\mathrm{X}} \mathrm{Na}^{+} \\
& \mathrm{A}_{\mathrm{Y}} \mathrm{A}_{\mathrm{Y}}+\mathrm{Na}^{+} \rightarrow \mathrm{A}_{\mathrm{Y}} \mathrm{A}_{\mathrm{Y}} \mathrm{Na}^{+} \\
& \mathrm{A}_{\mathrm{Y}} \mathrm{B}+\mathrm{Na}^{+} \rightarrow \mathrm{A}_{\mathrm{Y}} \mathrm{BNa}^{+}
\end{aligned}
$$

The energies of the reactions $\Delta_{\mathrm{r}} E$ were calculated as the difference between the total energies of the product and reactants:

$$
\Delta_{\mathrm{r}} E=E_{\text {prod }}-E_{\text {react }}
$$

The enthalpies of the reactions $\Delta_{\mathrm{r}} H^{\circ}(0)$ were obtained using $\Delta_{\mathrm{r}} E$ and the zero-point vibration energy corrections $\triangle \mathrm{ZPVE}$ :

$$
\begin{aligned}
& \Delta_{\mathrm{r}} H^{\circ}(0)=\Delta_{\mathrm{r}} E+\Delta \mathrm{ZPVE} \\
& \Delta \mathrm{ZPVE}=\frac{1}{2} h c\left(\sum \omega_{i \text { prod }}-\sum \omega_{i \text { react }}\right)
\end{aligned}
$$

where $h$ is the Plank's constant, $c$ is the speed of light in the free space, $\sum \omega_{i \text { prod }}$, and $\sum \omega_{i \text { react }}$ are the sums of the vibration frequencies of the product and reactants, respectively.

The enthalpies of the reactions (1)-(3) have been calculated under different basis sets, 6-31G(d), 6-31G(d, p), 6-311G(d), 6-311G(d, p), 6-31++G(d, p) and 6-311++G(d, p); the results are presented in Figure 5. For all three reactions, the similarity of the plots is observed. The general trend observed reveals the increase of the enthalpies of the reactions with the basis set extension. The difference between the lowest and highest values of $\Delta_{\mathrm{r}} H^{\circ}(0)$ for each reaction is about $50 \mathrm{~kJ} \cdot \mathrm{mol}^{-1}$, thereafter the uncertainties for the enthalpies of the reactions may be estimated as half of this difference, that is $\sim 25 \mathrm{~kJ} \cdot \mathrm{mol}^{-1}$. The values energies $\Delta_{\mathrm{r}} E, \Delta \mathrm{ZPVE}$, and enthalpies $\Delta_{\mathrm{r}} H^{\circ}(0)$ of the reactions obtained with the most extended basis set 6-311++G(d, p) are given in Table 3 . The results indicate the association processes are highly exothermic, that implies a strong interaction between the cation and dimer molecules and high energetic stability of the corresponding adducts formed. The data obtained here are close to the enthalpies of attachment of sodium ion to monomer molecules, $-196 \mathrm{~kJ} \cdot \mathrm{mol}^{-1}\left(\mathrm{~A}_{\mathrm{X}}+\mathrm{Na}^{+}=\right.$ $\left.\mathrm{A}_{\mathrm{X}} \mathrm{Na}^{+}\right),-227 \mathrm{~kJ} \cdot \mathrm{mol}^{-1}\left(\mathrm{~A}_{\mathrm{Y}}+\mathrm{Na}^{+}=\mathrm{A}_{\mathrm{Y}} \mathrm{Na}^{+}\right)$, and $-229 \mathrm{~kJ} \cdot \mathrm{mol}^{-1}\left(\mathrm{~B}+\mathrm{Na}^{+}=\mathrm{BNa}^{+}\right)$[20]. Apparently likeness of these results relates to the similarity of the interacting moieties of the monomer or dimer molecules with $\mathrm{Na}^{+}$ ion.

The Gibbs free energies $\Delta_{\mathrm{r}} G^{\circ}(T)$ of reactions (1)-(3) were calculated using the following equation:

$$
\Delta_{\mathrm{r}} G^{\circ}(T)=\Delta_{\mathrm{r}} H^{\circ}(T)-T \Delta_{\mathrm{r}} S^{\circ}(T)
$$

where $\Delta_{\mathrm{r}} H^{\circ}(T)$ is the enthalpy of the reaction at temperature $T, \Delta_{\mathrm{r}} S^{\circ}(T)$ is the change in entropy of the reaction. The thermodynamic functions of the $A_{X} A_{X}, A_{Y} A_{Y}, A_{Y} B, A_{X} A_{X} N^{+}, A_{Y} A_{Y} N^{+}$and $A_{Y} B N a+$, have been computed using the OpenThermo software [28], those for $\mathrm{Na}^{+}$gaseous ions are taken from [29]. The geometrical parameters and vibrational frequencies needed for the thermodynamic functions calculations have been obtained under 6-31G(d) basis set. The thermodynamic functions of the species are given in Table 4 for the temperature

Table 3. The reaction equations, energies $\Delta_{\mathrm{r}} E$, zero point vibrational energy corrections $\triangle \mathrm{ZPVE}$ and enthalpies $\Delta_{\mathrm{r}} H^{\circ}(0)$ of the reactions; in $\mathrm{kJ} \cdot \mathrm{mol}^{-1}$.

\begin{tabular}{ccccc}
\hline $\mathrm{N}$ & Reaction & $-\Delta_{\mathrm{r}} E$ & $\Delta \mathrm{ZPVE}$ & $-\Delta_{\mathrm{Y}} H^{\mathrm{o}}(0 \mathrm{~K})$ \\
1 & $\mathrm{~A}_{\mathrm{X}} \mathrm{A}_{\mathrm{X}}+\mathrm{Na}^{+}=\mathrm{A}_{\mathrm{X}} \mathrm{A}_{\mathrm{X}} \mathrm{Na}^{+}$ & 245.0 & 9.9 & 235 \\
2 & $\mathrm{~A}_{\mathrm{Y}} \mathrm{A}_{\mathrm{Y}}+\mathrm{Na}^{+}=\mathrm{A}_{\mathrm{Y}} \mathrm{A}_{\mathrm{Y} N \mathrm{Na}^{+}}$ & 247.4 & 4.9 & 243 \\
3 & $\mathrm{~A}_{\mathrm{Y}} \mathrm{B}+\mathrm{Na}^{+}=\mathrm{A}_{\mathrm{Y}} \mathrm{BNa}^{+}$ & 212.3 & 3.2 & 209 \\
\hline
\end{tabular}


Table 4. Thermodynamic functions of $A_{X} A_{X}, A_{Y} A_{Y}, A_{Y} B$ dimers and $A_{X} A_{X} N^{+}, A_{Y} A_{Y} N^{+}$and $A_{Y} B N a^{+}$adducts.

\begin{tabular}{|c|c|c|c|c|c|}
\hline & $T, \mathrm{~K}$ & $C_{\mathrm{p}}^{\mathrm{o}}, \mathrm{J} \cdot \mathrm{mol}^{-1} \cdot \mathrm{K}^{-1}$ & $S^{\circ}(T), \mathrm{J} \cdot \mathrm{mol}^{-1} \cdot \mathrm{K}^{-1}$ & $H^{\mathrm{o}}(T)-H^{\mathrm{o}}(0), \mathrm{kJ} \cdot \mathrm{mol}^{-1}$ & $\Phi^{\mathrm{o}}(T)^{\mathrm{a}}, \mathrm{J} \cdot \mathrm{mol}^{-1} \cdot \mathrm{K}^{-1}$ \\
\hline \multirow{9}{*}{$\mathrm{A}_{X} \mathrm{~A}_{X}$} & 298.15 & 384.91 & 671.75 & 63.53 & 458.68 \\
\hline & 300 & 387.16 & 674.33 & 64.30 & 460.00 \\
\hline & 400 & 495.93 & 800.83 & 108.53 & 529.50 \\
\hline & 500 & 590.51 & 921.98 & 163.00 & 595.98 \\
\hline & 600 & 668.09 & 1036.74 & 226.06 & 659.97 \\
\hline & 700 & 731.26 & 1144.63 & 296.14 & 721.58 \\
\hline & 800 & 783.35 & 1245.79 & 371.95 & 780.86 \\
\hline & 900 & 826.97 & 1340.64 & 452.52 & 837.84 \\
\hline & 1000 & 863.97 & 1429.74 & 537.12 & 892.62 \\
\hline \multirow{9}{*}{$\mathrm{A}_{X} \mathrm{~A}_{X} \mathrm{Na}^{+}$} & 298.15 & 399.61 & 681.75 & 65.22 & 463.01 \\
\hline & 300 & 401.77 & 684.23 & 65.96 & 464.36 \\
\hline & 400 & 513.82 & 815.43 & 111.83 & 535.84 \\
\hline & 500 & 610.35 & 940.79 & 168.19 & 604.40 \\
\hline & 600 & 689.17 & 1059.29 & 233.31 & 670.44 \\
\hline & 700 & 753.17 & 1170.50 & 305.53 & 734.02 \\
\hline & 800 & 805.87 & 1274.62 & 383.57 & 795.16 \\
\hline & 900 & 849.95 & 1372.16 & 466.42 & 853.91 \\
\hline & 1000 & 887.36 & 1463.70 & 553.34 & 910.36 \\
\hline \multirow{9}{*}{$A_{Y} A_{Y}$} & 298.15 & 383.84 & 661.65 & 62.79 & 451.05 \\
\hline & 300 & 385.93 & 664.03 & 63.50 & 452.36 \\
\hline & 400 & 495.22 & 790.26 & 107.64 & 521.16 \\
\hline & 500 & 590.01 & 911.27 & 162.05 & 587.17 \\
\hline & 600 & 667.64 & 1025.95 & 225.07 & 650.84 \\
\hline & 700 & 730.77 & 1133.78 & 295.09 & 712.22 \\
\hline & 800 & 782.80 & 1234.86 & 370.85 & 771.29 \\
\hline & 900 & 826.37 & 1329.65 & 451.37 & 828.12 \\
\hline & 1000 & 863.35 & 1418.68 & 535.91 & 882.77 \\
\hline \multirow{10}{*}{$\mathrm{A}_{Y} \mathrm{~A}_{\mathrm{Y}} \mathrm{Na}^{+}$} & 298.15 & 408.10 & 690.29 & 67.24 & 464.77 \\
\hline & 300 & 410.23 & 692.82 & 68.00 & 466.17 \\
\hline & 400 & 520.53 & 826.21 & 114.63 & 539.64 \\
\hline & 500 & 615.57 & 952.91 & 171.58 & 609.74 \\
\hline & 600 & 693.14 & 1072.24 & 237.15 & 676.98 \\
\hline & 650 & 726.21 & 1129.05 & 272.65 & 709.59 \\
\hline & 700 & 756.09 & 1183.98 & 309.72 & 741.52 \\
\hline & 800 & 807.92 & 1288.43 & 388.00 & 803.43 \\
\hline & 900 & 851.25 & 1386.17 & 471.02 & 862.81 \\
\hline & 1000 & 888.09 & 1477.81 & 558.04 & 919.77 \\
\hline \multirow{9}{*}{$A_{Y} B$} & 298.15 & 432.82 & 721.32 & 70.38 & 485.27 \\
\hline & 300 & 435.19 & 724.01 & 71.18 & 486.73 \\
\hline & 400 & 557.73 & 866.31 & 120.94 & 563.96 \\
\hline & 500 & 662.62 & 1002.40 & 182.13 & 638.15 \\
\hline & 600 & 747.97 & 1131.03 & 252.81 & 709.69 \\
\hline & 700 & 817.16 & 1251.71 & 331.18 & 778.59 \\
\hline & 800 & 874.08 & 1364.66 & 415.83 & 844.87 \\
\hline & 900 & 921.69 & 1470.44 & 505.69 & 908.57 \\
\hline & 1000 & 962.05 & 1569.69 & 599.93 & 969.76 \\
\hline \multirow{10}{*}{$\mathrm{AY}_{Y} \mathrm{BNa}^{+}$} & 298.15 & 458.25 & 752.781 & 75.06 & 501.03 \\
\hline & 300 & 460.65 & 755.62 & 75.91 & 502.60 \\
\hline & 400 & 584.37 & 905.44 & 128.28 & 584.74 \\
\hline & 500 & 689.48 & 1047.52 & 192.15 & 663.22 \\
\hline & 600 & 774.64 & 1181.03 & 265.51 & 738.52 \\
\hline & 700 & 843.49 & 1305.80 & 346.53 & 810.75 \\
\hline & 750 & 873.10 & 1365.02 & 389.46 & 845.74 \\
\hline & 800 & 900.05 & 1422.24 & 433.80 & 879.99 \\
\hline & 900 & 947.32 & 1531.06 & 526.23 & 946.36 \\
\hline & 1000 & 987.40 & 1633.00 & 623.02 & 1009.98 \\
\hline
\end{tabular}

${ }^{\mathrm{a}} \Phi^{\circ}(T)=-\left[H^{\circ}(T)-H^{\circ}(0)-T S^{\circ}(T)\right] / T$ is the reduced Gibbs free energy. 
range between $298 \mathrm{~K}$ and $1000 \mathrm{~K}$. To find the enthalpies $\Delta_{\mathrm{r}} H^{\circ}(T)$, the enthalpy increments $H^{\circ}(T)-H^{\circ}(0)$ were used:

$$
\Delta_{\mathrm{r}} H^{\circ}(T)=\Delta_{\mathrm{r}} H^{\circ}(0)+\Delta_{\mathrm{r}}\left[H^{\circ}(T)-H^{\circ}(0)\right]
$$

where the values of $\Delta_{\mathrm{r}} H^{\circ}(0)$ were obtained using Equation (5) and the values of $\Delta_{\mathrm{r}} E$ calculated with 6-311++G(d, p) basis set.

The plot of the Gibbs free energies of reactions (1), (2) and (3) are presented in Figure 6. The values of $\Delta_{\mathrm{r}} G^{\circ}(T)$ are negative in a broad temperature range, this indicates that the attachment processes are spontaneous; $\Delta_{\mathrm{r}} G^{\circ}(T)$ become positive at temperatures higher than $1700 \mathrm{~K}$ for the reaction (1), and $2000 \mathrm{~K}$ for (2) and (3). For the reverse process it is evident that their corresponding adducts are stable with respect of the detachment of $\mathrm{Na}^{+}$ ion in a broad temperature range (Figure 7).

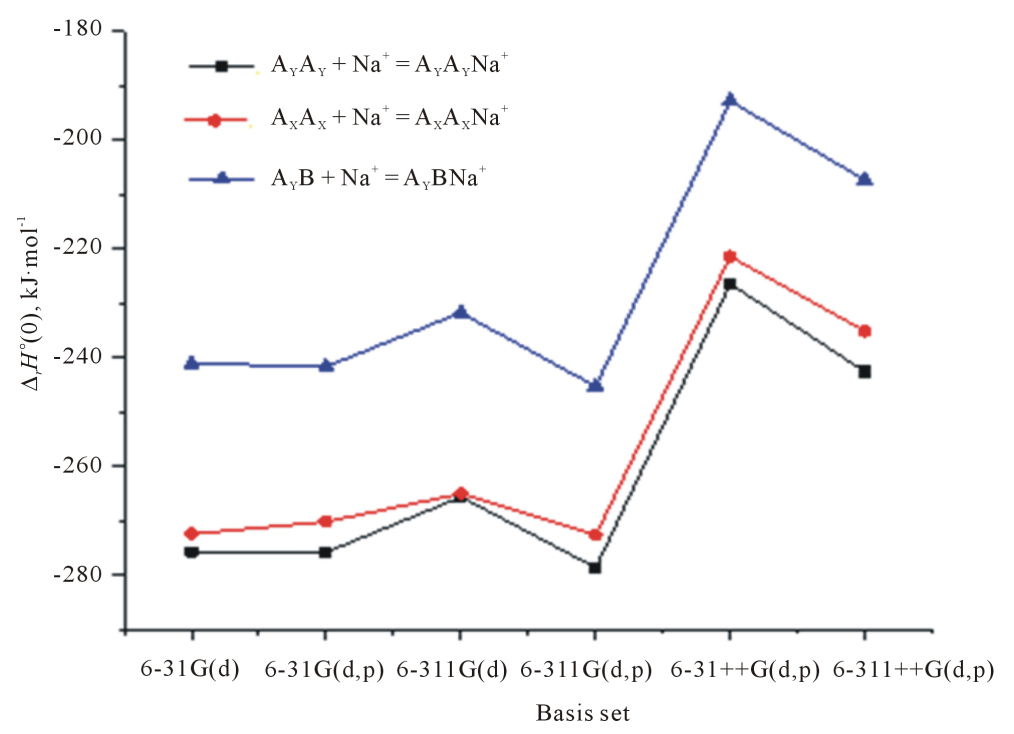

Figure 6. The calculated enthalpies of the reactions (1)-(3) vs. basis set.

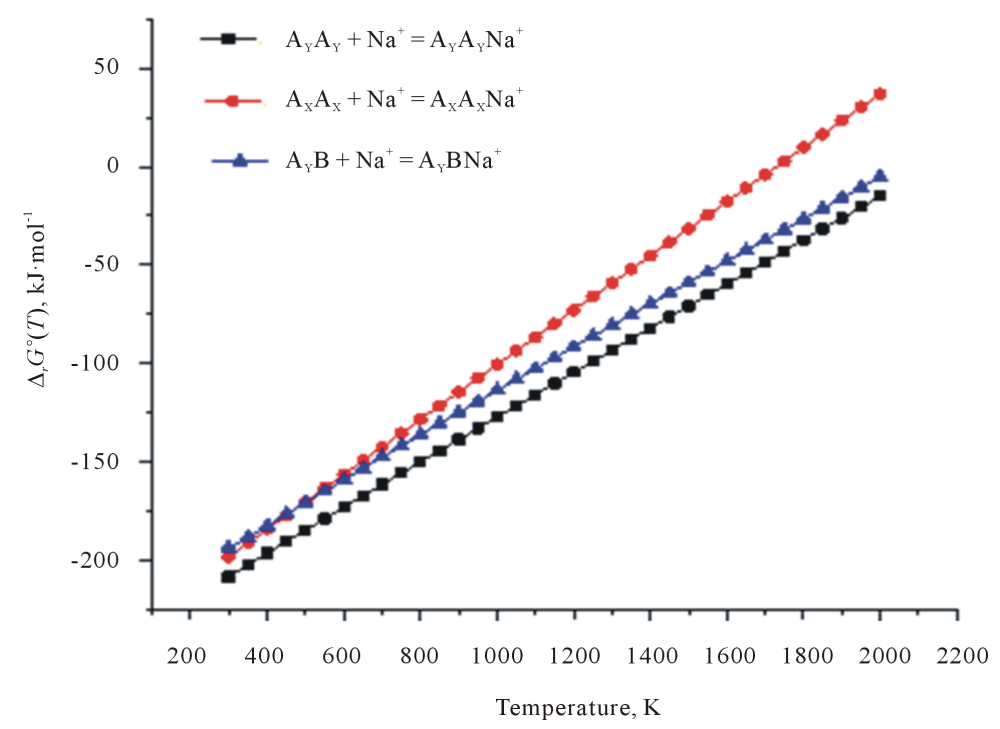

Figure 7. Gibbs free energy vs. temperature for the reactions $A_{X} A_{X}+\mathrm{Na}^{+}=$ $A_{X} A_{X} N^{+}, A_{Y} A_{Y}+\mathrm{Na}^{+}=A_{Y} A_{Y} N^{+}$and $A_{Y} B+N^{+}=A_{Y} B N a^{+}, 6-311++G(d, p)$ basis set. 


\section{Conclusions}

The attachment of $\mathrm{Na}^{+}$ion to the dimers $A_{X} A_{X}, A_{Y} A_{Y}, A_{Y} B$ to form adducts has been studied using the DFT/B3LYP method. The geometrical structures, vibrational spectra of the dimer molecules and their corresponding adducts due to $\mathrm{Na}^{+}$attachment have been determined. Position of $\mathrm{Na}^{+}$attachment is dictated by negative atomic charges occurrence, appropriate internuclear separations and steric factors. In the adducts $\mathrm{A}_{X} \mathrm{~A}_{X} \mathrm{Na}^{+}$ and $A_{Y} A_{Y} \mathrm{Na}^{+}$, the sodium ion is linked to nitrogen and oxygen atoms; while in the $A_{Y} B$ molecule nitrogen atoms are screened by the acetyl groups, and therefore $\mathrm{Na}^{+}$sticks to three oxygen atoms instead.

The scrutiny of the calculated IR spectra revealed the general feature for all species, which is an existence of three regions composed of the similar vibrational bands which have been assigned to the certain functional groups of atoms, $\mathrm{NH}_{2}, \mathrm{CH}, \mathrm{OH}, \mathrm{COC}$, and other fragments. The structural resemblance of the species also has been brought to the similarity of the spectra. Thermodynamic characteristics of attachment have been determined. The exothermicity and spontaneity character of adducts formation have been ascertained.

\section{Acknowledgements}

The authors are grateful to The Nelson Mandela African Institution of Science and Technology, and The British Gas (BG group) for the sponsorship. In a special way we acknowledge a valuable assistance and service by the School of Computational and Communication Science and Engineering.

\section{References}

[1] Simons, J.P. (2009) Good Vibrations: Probing Biomolecular Structure and Interactions through Spectroscopy in the Gas Phase. Molecular Physics: An International Journal at the Interface between Chemistry and Physics, 107, 24352458.

[2] Petrov, M., Lymperakis, L., Friák, M. and Neugebauer, J. (2012) Ab Initio Based Conformational Study of the Crystalline $\alpha$-Chitin. Biopolymers, 99, 22-34. http://dx.doi.org/10.1002/bip.22131

[3] Fattahi, A., Ghorat, M., Pourjavadi, A., Kurdtabar, M. and Torabi, A.A. (2008) DFT/B3LYP Study of Thermochemistry of D-Glucosamine, a Representative Polyfunctional Bioorganic Compound. Scientia Iranica, 15, 422-429.

[4] Becke, A.D. (2014) Perspective: Fifty Years of Density-Functional Theory in Chemical Physics. The Journal of Chemical Physics, 140, 18A301. http://dx.doi.org/10.1063/1.4869598

[5] Cohen, A.J., Mori-Sánchez, P. and Yang, W. (2011) Challenges for Density Functional Theory. Chemical Reviews, 112, 289-320. http://dx.doi.org/10.1021/cr200107z

[6] Peña, I., Kolesniková, L., Cabezas, C., Bermúdez, C., Berdakin, M., Simão, A. and Alonso, J.L. (2014) The Shape of D-Glucosamine. Physical Chemistry Chemical Physics, 16, 23244-23250. http://dx.doi.org/10.1039/C4CP03593C

[7] Onoka, I., Pogrebnoi, A. and Pogrebnaya, T. (2014) Geometrical Structure, Vibrational Spectra and Thermodynamic Properties of Chitosan Constituents by DFT Method. International Journal of Materials Science and Applications, 3, 121-128. http://dx.doi.org/10.11648/j.ijmsa.20140304.11

[8] Danielsen, S., Vårum, K.M. and Stokke, B.T. (2004) Structural Analysis of Chitosan Mediated DNA Condensation by AFM: Influence of Chitosan Molecular Parameters. Biomacromolecules, 5, 928-936. http://dx.doi.org/10.1021/bm034502r

[9] Sionkowska, A., Wisniewski, M., Skopinska, J., Kennedy, C.J. and Wess, T.J. (2004) Molecular Interactions in Collagen and Chitosan Blends. Biomaterials, 25, 795-801. http://dx.doi.org/10.1016/S0142-9612(03)00595-7

[10] Lehninger, A.L. (2004) Principles of Biochemistry. 4th Edition, W.H. Freeman, New York.

[11] Amaral, I.F., Granja, P.L. and Barbosa, M.A. (2005) Chemical Modification of Chitosan by Phosphorylation: An XPS, FT-IR and SEM Study. Journal of Biomaterials Science, Polymer Edition, 16, 1575-1593. http://dx.doi.org/10.1163/156856205774576736

[12] Luo, Y.C. and Wang, Q. (2013) Recent Advances of Chitosan and Its Derivatives for Novel Applications in Food Science. Journal of Food Processing and Beverages, 1, 13.

[13] Aranaz, I., Mengíbar, M., Harris, R., Paños, I., Miralles, B., Acosta, N., Galed, G. and Heras, Á. (2009) Functional Characterization of Chitin and Chitosan. Current Chemical Biology, 3, 203-230.

[14] El-hefian, E.A., Nasef, M.M. and Yahaya, A.H. (2010) Preparation and Characterization of Chitosan/Polyvinyl Alcohol Blends-A Rheological Study. E-Journal of Chemistry, 7, S349-S357. http://dx.doi.org/10.1155/2010/275135

[15] Benavente, M. (2008) Adsorption of Metallic Ions onto Chitosan: Equilibrium and Kinetic Studies. Licentiate Thesis, KTH, Stockholm. 
[16] Tharun, J., Hwang, Y., Roshan, R., Ahn, S., Kathalikkattil, A.C. and Park, D.W. (2012) A Novel Approach of Utilizing Quaternized Chitosan as a Catalyst for the Eco-Friendly Cycloaddition of Epoxides with $\mathrm{CO}_{2}$. Catalysis Science \& Technology, 2, 1674-1680. http://dx.doi.org/10.1039/c2cy20137b

[17] Prashanth, K.V.H. Advancement of Chitosan Based Nanoparticles for Present and Future Interests. Department of Meat, Fish and Poultry Technology CSIR-Central Food and Technological Research Institute, Mysore.

[18] Patrulea, V., Negrulescu, A., Mincea, M.M., Pitulice, L.D., Spiridon, O.B. and Ostafe, V. (2013) Optimization of the Removal of Copper (II) Ions from Aqueous Solution on Chitosan and Cross-Linked Chitosan Beads. BioResources, 8, 1147-1165. http://dx.doi.org/10.15376/biores.8.1.1147-1165

[19] Terreux, R., Domard, M., Viton, C. and Domard, A. (2006) Interactions Study between the Copper II Ion and Constitutive Elements of Chitosan Structure by DFT Calculation. Biomacromolecules, 7, 31-37. http://dx.doi.org/10.1021/bm0504126

[20] Emmanuel, M., Pogrebnoi, A. and Pogrebnaya, T. (2015) Interactions between Sodium Ion and Constituents of Chitosan: DFT Study. International Journal of Materials Science and Applications, 4, 303-313.

[21] HyperChem ${ }^{(\mathrm{TM})}$, H., Inc., 1115 NW 4th Street, Gainesville, Florida 32601, USA.

[22] Granovsky, A.A. (2014) Firefly Version 8.1.0. http://classic.chem.msu.su/gran/firefly/index.html

[23] Schmidt, M.W., Baldridge, K.K., Boatz, J.A., Elbert, S.T., Gordon, M.S., Jensen, J.H., Koseki, S., Matsunaga, N., Nguyen, K.A., Su, S., Windus, T.L., Dupuis, M. and Montgomery, J.A. (1993) General Atomic and Molecular Electronic Structure System. Journal of Computational Chemistry, 14, 1347-1363. http://dx.doi.org/10.1002/jcc.540141112

[24] Bode, B.M. and Gordon, M.S. (1998) Macmolplt: A Graphical User Interface for GAMESS. Version 7.4.2. Journal of Molecular Graphics and Modelling, 16, 133-138. http://dx.doi.org/10.1016/S1093-3263(99)00002-9

[25] Zhurko, G.A. and Zhurko, D.A. Chemcraft. Version 1.7 (Build 132). www.chemcraftprog.com

[26] Kunjachan, S., Jose, S. and Lammers, T. (2010) Understanding the Mechanism of Ionic Gelation for Synthesis of Chitosan Nanoparticles Using Qualitative Techniques. Asian Journal of Pharmaceutics, 4, 148-153. http://www.asiapharmaceutics.info/text.asp?2010/4/2/148/68467 http://dx.doi.org/10.4103/0973-8398.68467

[27] Sobahi, T.R., Makki, M.S.I. and Abdelaal, M.Y. (2013) Carrier-Mediated Blends of Chitosan with Polyvinyl Chloride for Different Applications. Journal of Saudi Chemical Society, 17, 245-250. http://dx.doi.org/10.1016/j.jscs.2011.03.015

[28] Tokarev, K. (2007-2009) OpenThermo. v.1.0 Beta 1 (C) ed. http://openthermo.software.informer.com

[29] Gurvich, L.V., Yungman, V.S., Bergman, G.A., Veitz, I.V., Gusarov, A.V., Iorish, V.S., Leonidov, V.Y., Medvedev, V.A., Belov, G.V., Aristova, N.M., Gorokhov, L.N., Dorofeeva, O.V., Ezhov, Y.S., Efimov, M.E., Krivosheya, N.S., Nazarenko, I.I., Osina, E.L., Ryabova, V.G., Tolmach, P.I., Chandamirova, N.E. and Shenyavskaya, E.A. (1992-2000) Thermodynamic Properties of Individual Substances. Ivtanthermo for Windows Database on Thermodynamic Properties of Individual Substances and Thermodynamic Modeling Software. Version 3.0. Glushko Thermocenter of RAS, Moscow. 